\title{
LAGRANGIAN DRIFTER MODELLING OF AN EXPERIMENTAL RIP CURRENT
}

\author{
Leandro Suarez $^{12}$, Rodrigo Cienfuegos ${ }^{2}$, Cristian Escauriaza $^{2}$, Eric Barthélemy ${ }^{1}$ and Hervé Michallet ${ }^{1}$ \\ A non-uniform alongshore wave forcing on an experimental uneven mobile bathymetry create mean circulation on a rip channel. \\ A 2D numerical hydrodynamic model that integrates the non-linear shallow-water equations in a shock-capturing finite-volume \\ framework is used to validate the nearshore circulation, and drifters displacement.
}

Keywords: rip currents, non-linear shallow-water equations, lagrangian drifters

\section{INTRODUCTION}

When approaching the coast the propagation of random wave fields over uneven bathymetries triggers spatio-temporal non-uniformities in wave breaking, inducing energy dissipation gradients in the surf zone. These gradients generate mean currents, important for the nearshore, because of their influence in mixing, dispersion, sediment transport and beach morphology.

Under close to normal wave incidence conditions, these energy dissipation gradients in the nearshore zone participate in the formation of rip currents (figure 1), which are strong offshore directed jets, that can be hazardous for swimmers. The dynamics of rip currents show modulations in time and space due to wave groupiness, the tidal cycle, infragravity motion, Very Low Frequency (VLF) motions and swell (MacMahan et al. [2006]). The use of Lagrangian drifters and Lagrangian Coherent Structures (LCS) analysis have been recently applied to better assess the influence of VLF in the rip currents ejections (Reniers et al. [2010])

In this work we aim at investigating and characterizing with a numerical model the nearshore circulation forced by a random wave field propagating over non-uniform bathymetry in comparison with 3D morphodynamic laboratory experiments of rip channels.

\section{METHODS}

\section{Laboratory Experiments}

The experiments (Michallet et al. [2010]) took place in the LHF (SOGREAH/Grenoble-INP) wave tank (figure figure 2), with dimensions of $30 \times 30 \mathrm{~m}^{2}$. The mobile bed consisted of a layer of fine sand with $d_{50}=$ $164 \mathrm{~mm}$ over the rigid bottom. The waves originate from a 60 parallel segmented piston-type wavemaker, of $50 \mathrm{~cm}$ width each and covering the $30 \mathrm{~m}$ tank width, allowing to produce a differential wave forcing between the segments.

To access the water levels and velocities during the experiment, three fixed capacitive wave gauges located at $X=5 \mathrm{~m}$ and $Y=8.17 \mathrm{~m}, Y=15.0 \mathrm{~m}, Y=21.75 \mathrm{~m}$ respectively were used to obtain incident wave conditions. A moving sliding rail equipped with capacitive wave gauges can take cross-shore profile measures, and can provide information about longshore profiles as we move it alongshore.

Velocity measurements were obtained with three Acoustic Doppler Velocimeter (ADV), one fixed at $X=$ $10.00 \mathrm{~m}, Y=15.00 \mathrm{~m}$, and two located on the sliding rail. The ADV provides the three components of the velocity at a fixed point located at $4-8 \mathrm{~cm}$ above the bed, depending on the postion of the sliding rail.

The acquisition frequency is set to $50 \mathrm{~Hz}$ for the capacitive wave gauges, and to $64 \mathrm{~Hz}$ for the ADV velocities.

A laser profiler mounted on a motorized trolley located on the sliding rail measured the beach morphology every day, in the bathymetric survey area, between $7.84 m<X<22.84 \mathrm{~m}$ in the cross-shore direction, and $3.12 m<Y<28.02 m$ in the longshore direction, this area being limited by the sliding rail configuration.

The wave climate consisted in irregular shore-normal waves complying with a JONSWAP spectrum. Different wave conditions were tested during the experiment, but in this article we only focus on a wave sequence of 20 minutes concerning the numerical modelling $\left(H_{m 0}=18 \mathrm{~cm}, T_{p}=3.5 \mathrm{~s}\right)$.

In order to create an alongshore non-uniformity in the incoming waves, the wave amplitude in the center of the wave flume was damped, resulting in alongshore variations of $H_{r m s}$ as can be seen in figure 3. This

\footnotetext{
${ }^{1}$ LEGI UMR 5519, Domaine universitaire, BP 53, 38041 Grenoble cedex 9, France

${ }^{2}$ Departamento de Ingenieria Hidráulica y Ambiental, Pontificia Universidad Católica de Chile, Vicuña Mackenna, Chile
} 


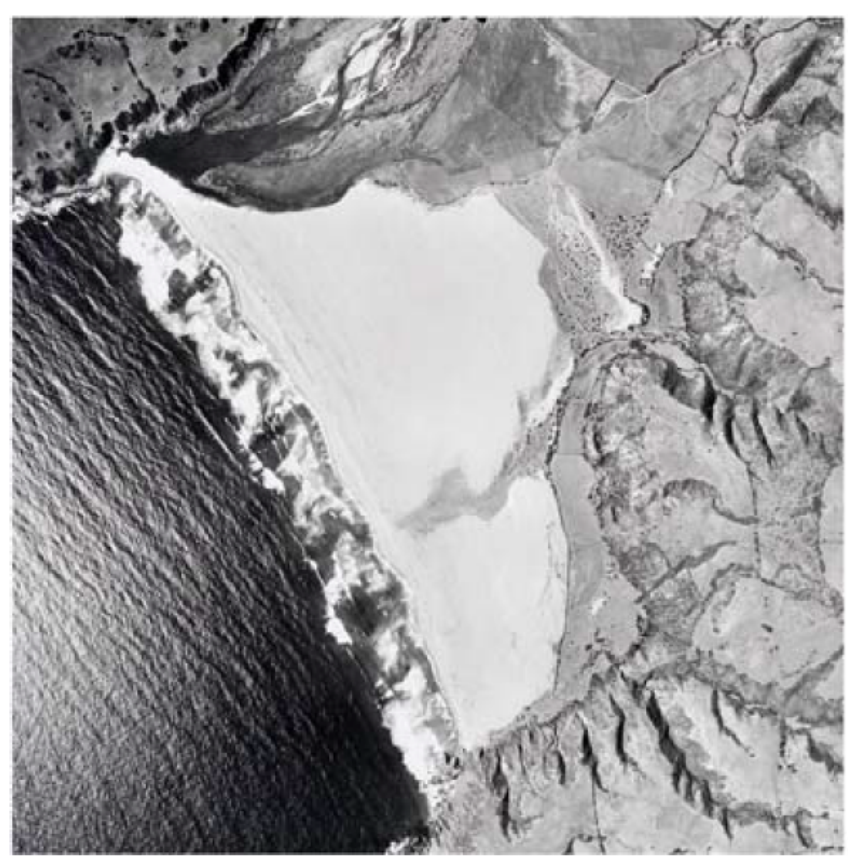

Figure 1: Rip currents in the Tunquen Beach, Chile (from Martínez \& Salinas [2009])

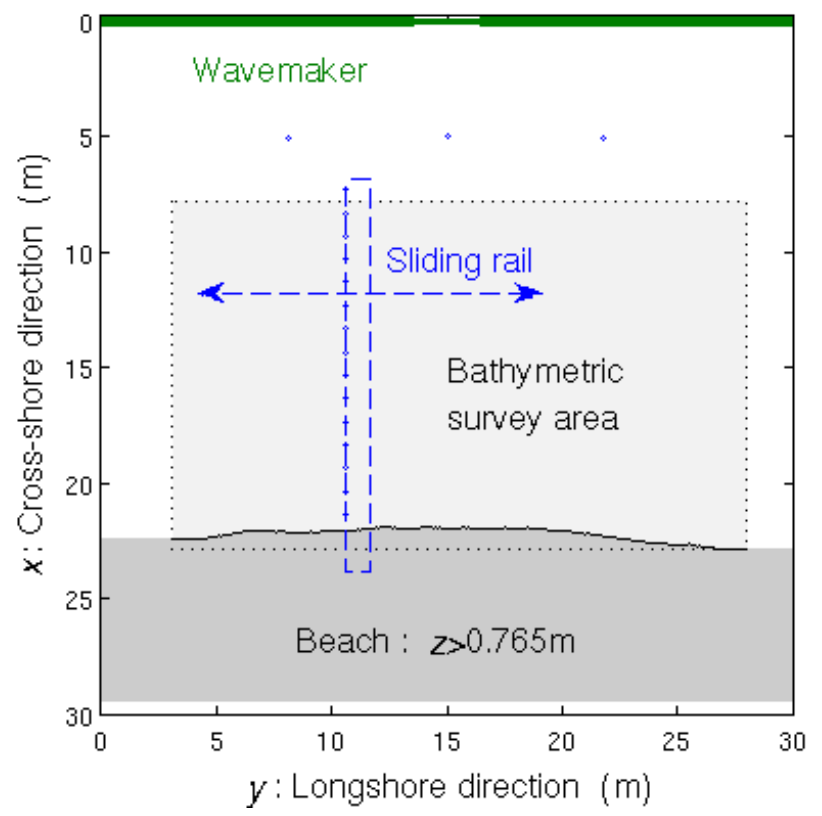

Figure 2: Schematics representation of LHF wave tank. the $X$ axis corresponds to the cross-shore position, the wavemaker is located at $X=0 \mathrm{~m}$, the shoreline is at $X \approx 22 \mathrm{~m}$. The $Y$ axis corresponds to the alongshore position 


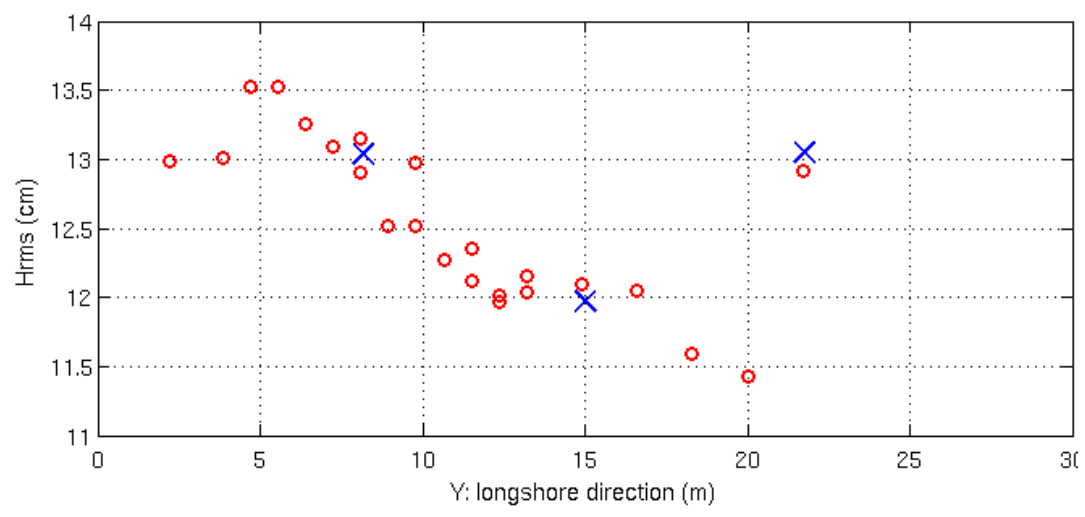

Figure 3: Incident wave climate: $H_{r m s}$ obtained by the capacitive wave gauges, located at $X=5 \mathrm{~m}$ from the wavemaker (blue X), and at $X=7.30 \mathrm{~m}$ (red O). We clearly observe a smaller $H_{r m s}$ in the middle of the tank, result of the damped motion of the wavemakers located in the middle

alongshore non-unifomity enhanced a rip instability. We define $H_{r m s}$ as the root mean square of the wave height sequence, and $H_{m 0}$ as the significant wave height estimated by integrating the wave spectrum in the full frequency range. The relation between these two terms is $H_{m 0}=1.416 H_{r m s}$.

We consider the initial beach at $t=00 h 00$, when the wave forcing considered starts. This original bathymetry is relatively uniform alongshore, with an alongshore bar at $x \approx 13 \mathrm{~m}$. The experiment we consider lasts for $51 h 40$, with a wave sequence of 20 minutes, repeated continuously. Every 20 minutes the sliding rail was moved alongshore to gather data in the whole survey area.

There are two phenomena that explain the bathymetric evolution. The first one consist in the wave nonuniformity alongshore, which create rip channels and an heterogeneity alongshore. The second one is related to the mild wave conditions, and results in an onshore sediment transport (figure 4). Therefore, during this experiment, the beach never reached a quasi-steady state. The characteristic time of this two phenomena are different, the accretion occurring at a greater time scale than the alongshore non-uniformity evolution.

The alongshore wave forcing non-uniformity results in an alongshore non-uniformity in the bathymetry, and the formation of rip channels (figure 5). At $t=26 h 00$, we observe an onshore migration of the bar, as well as the formation of rip channels and shallow shoals. at $t=51 h 40$, we observe the filling of the rip channels previously formed, as the accretion phase continues.

During the LHF experiment, rip currents characteristics were investigated with the use of Drifters measurements (Castelle et al. [2010]). The drifters consisted in balloons filled with water, of diameter 5-10 $\mathrm{cm}$ deployed in the surf zone during the different runs, for a period of 30 to 60 minutes. The duration of the drifters experiments compared to the morphological time-scale of the experiment allows us to assume little evolution of the bathymetry during the drifters movements.

A shore-mounted video-camera was used to track the drifters during the wave forcing (see figure 6): The images obtained were then rectified to obtain the Cartesian coordinates of the drifters. The drifters movement were obtained by a semi-automatic method, by indicating manually the drifter position every 6 seconds.

Cross-shore and alongshore velocities were estimated from a linear interpolation in position and time of each sequential position of the drifter position at a $1 \mathrm{~s}$ time step over a $30 \mathrm{~s}$ duration, and mean currents were calculated. For more details the reader is referred to Castelle et al. [2010]

\section{Numerical Modelling}

The numerical model is a 2D depth-averaged model, using the Non-linear Shallow Water Equations (NSWE), valid for long waves. The main assumptions of this set of equations are incompressibility, homogeneous fluid and hydrostatic pressure distribution. 


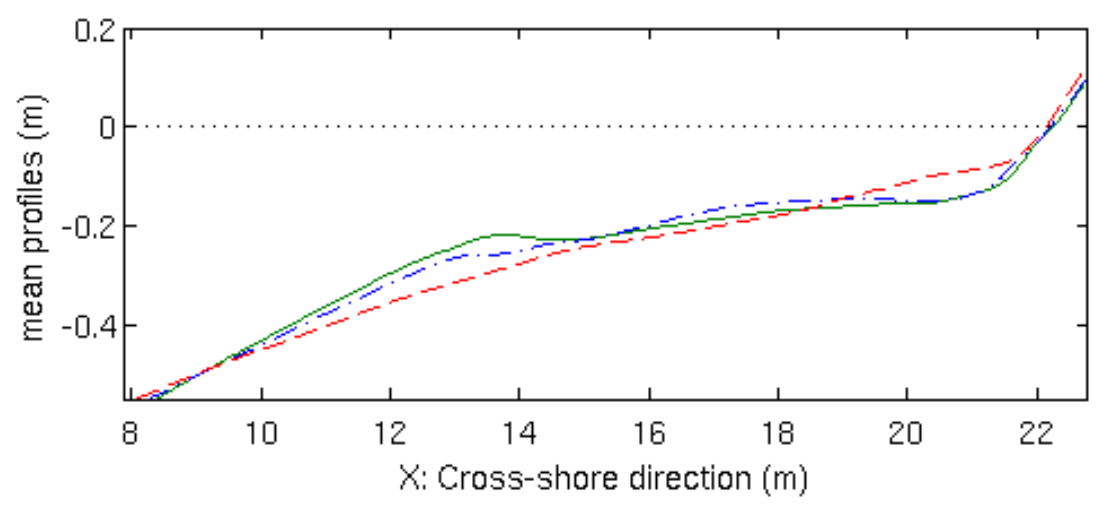

Figure 4: Mean cross-shore bathymetric profiles at $t=0 h 00$ (green line), $t=26 h 00$ (blue dash) and $t=51 h 40$ (red dot dash). Still water level is represented in black dots.
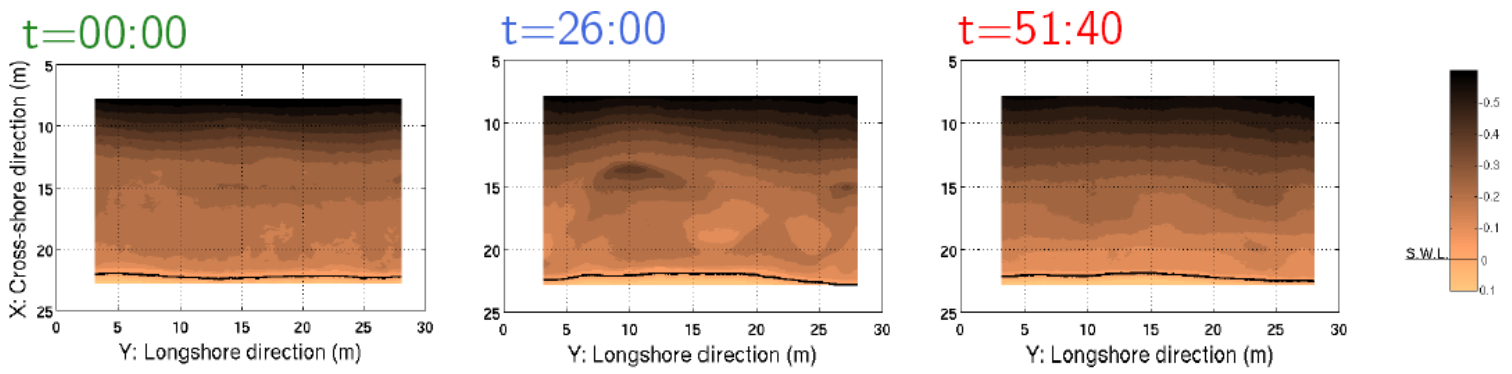

Figure 5: Beach Bathymetry at $t=0 h 00$ (a), $t=26 h 00$ (b) and $t=51 h 40$ (c). The still water level is marked by a thick black line

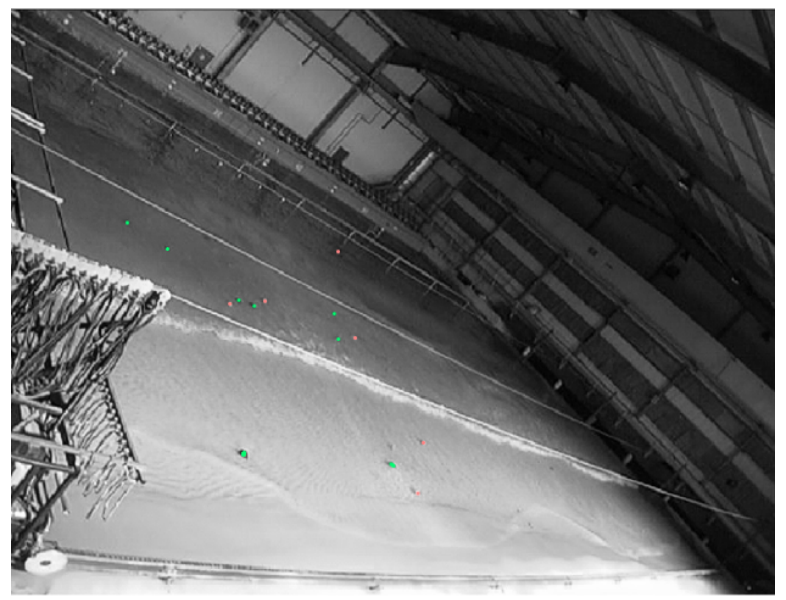

Figure 6: Sample of captured video images with drifters (from Castelle et al. [2010]). 
The non-dimensional form of the NSWE can be written:

$$
\frac{\partial Q}{\partial t}+\frac{\partial \bar{F}}{\partial x}+\frac{\partial \bar{G}}{\partial y}=S(Q)
$$

where $Q$ is the vector of hydrodynamic variables, function of $h$ the water depth, $u$ and $v$ respectively the cross-shore and longshore depth-averaged velocities, $\bar{F}$ and $\bar{G}$ represent the flux vectors in each Cartesian direction, and $S$ is the source term vector considering bed slope and friction. The terms of the equation are defined as:

$$
\begin{gathered}
Q=\left(\begin{array}{c}
h \\
h u \\
h v
\end{array}\right), \bar{F}(Q)=\left(\begin{array}{c}
h u \\
h u^{2}+\frac{1}{2 F r^{2}} h^{2} \\
h u v
\end{array}\right), \bar{G}(Q)=\left(\begin{array}{c}
h v \\
h u v \\
h v^{2}+\frac{1}{2 F r^{2}} h^{2}
\end{array}\right) \\
S(Q)=\left(\begin{array}{c}
0 \\
-\frac{h}{F r^{2}} \frac{\partial z}{\partial x}-S_{f x} \\
-\frac{h}{F r^{2}} \frac{\partial z}{\partial y}-S_{f y}
\end{array}\right)
\end{gathered}
$$

with $F r$ as the Froude number, $\frac{\partial z}{\partial x}$ and $\frac{\partial z}{\partial y}$ as the bed-slope, $S_{f x}$ and $S_{f y}$ as the friction source term

The non-dimensional form of the NSWE, given by Equations (1), are solved using a finite volume wellbalanced scheme, which incorporates the friction and bed-slope in the momentum source terms (Marche et al. [2007],Guerra et al. [2010]) . The numerical procedure consists of an initial step in which the friction source term in the momentum equations is incorporated employing a semi-implicit method. (Liang \& Marche [2009])

In a second hyperbolic NSWE step, the variables are reconstructed at the cell interfaces and the fluxes are found through the solution of the Riemann problem at the cell interfaces using a non-conservative form of the governing equations. This methodology gives the numerical model the well-balanced property by considering the bed-slope in the spatial discretization schemes using a MUSCL type reconstruction method to reach a second order accuracy. The discretized form of the governing equations is integrated in time using a multistage Runge-Kutta scheme.

The drifters motions are modelled by a Lagrangian Particle Tracking model (Escauriaza \& Sotiropulos [2011]). One assumption we make is that the drifters have no mass, and therefore no inertia forces, so they follow exactly the flow. The governing equation of the model to obtain the particle trajectory is the following:

$$
\frac{d x_{i}}{d t}=v_{i}
$$

with $x_{i}$ and $v_{i}$ represent the $i$ th component of the drifter position and velocity. With this Lagrangian Particle Tracking model, we are able to follow particles of water during the wave forcing.

The model boundary conditions are shown in figure 7: the boundaries $2(Y=0 \mathrm{~m})$ and $3(Y=30 \mathrm{~m})$ corresponds to closed boundaries, to reflect the closed basin. The boundary $4(X=25 \mathrm{~m})$ corresponds to a moving shoreline, with a dry/wet interface (Marche et al. [2007]). The boundary $1(X=5 \mathrm{~m}$ ) consider an absorption/generation condition (Cienfuegos et al. [2007], Mignot \& Cienfuegos [2009])

For the present simulation, we considered a rectangular grid, with a regular spacing $\Delta x=\Delta y=0.10 \mathrm{~m}$, leading to roughly 60,000 nodes.

The absorption/generation condition at $X=5 \mathrm{~m}$ simply allows to propagate waves out of domain at this offshore boundary. The incoming wave height is specified through the incoming Riemann invariant. The water depth and velocity at the boundary is hence computed combining both this incoming invariant and the outgoing one. For the wave height input, the wave height near the wavemaker was not available. Therefore we considered the closest wave gauges to the wavemaker, that consisted in three static wave gauges located at 5 meters from the wavemaker, precisely at $X=5 \mathrm{~m}$, and $Y=8.17 \mathrm{~m}, Y=15 \mathrm{~m}, Y=21.75 \mathrm{~m}$ respectively. The wave input at each node is then interpolated alongshore, using the three wave gauges. Resulting wave forcing is shown in figure 8.

Concerning the incident wave condition, there is a difference between the experimental data, and the numerical model. As the absorption/generation condition is an open boundary the "numerical basin" produces 


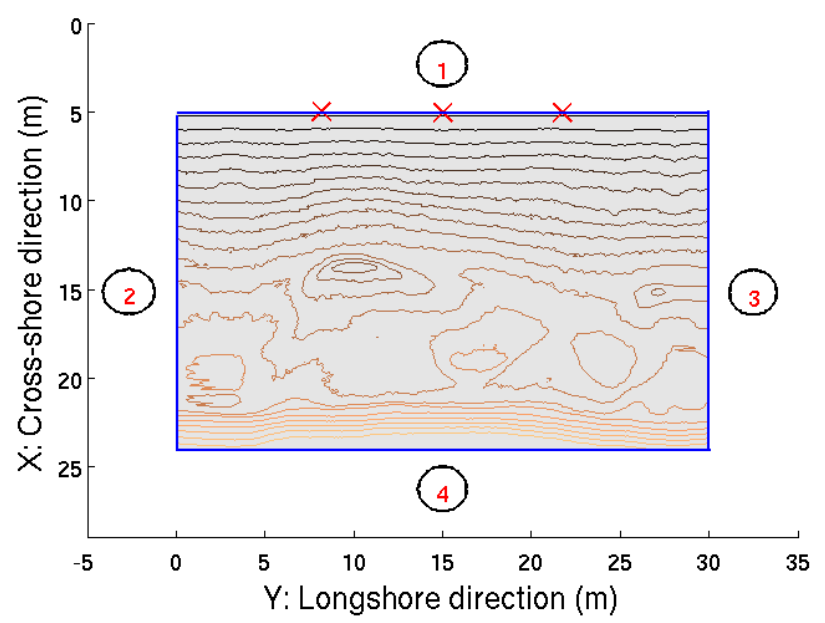

Figure 7: Boundary conditions of the numerical model. The red crosses mark the location of the wave gauges used for estimating the wave input

no reflection at this boundary while the wave basin is a closed one. The latter implies that reflection at the wavemaker is not included in the numerical model, so that resonant conditions due to the semi-enclosed basin in the experimental data will not be amplified in the simulations. The influence of the wavemaker can be seen mostly in the resonant modes of the basin, occurring at low frequencies. For our numerical model, we prefer to use a high-pass filter and not to force incident wave conditions with infragravity energy. The model should be able to transfer energy from the short-wave band to the low frequency band, without resonant mode amplification.

\section{MODEL VALIDATION}

The model is validated with the bathymetry shown in figure $5 \mathrm{~b}$ ) which exhibits two rip channels formed, at $Y=10 \mathrm{~m}$ and $Y=26 \mathrm{~m}$.

We first validate the numerical model by checking the wave height statistical properties. To that end, we compare $H_{r m s}$ in a cross-shore profile, located at the middle of the basin alongshore, at $Y=15 \mathrm{~m}$. The spectra were calculated over a 20 minute sequence, at a $50 \mathrm{~Hz}$ frequency for both the wave gauges and the numerical data. The first spectrum 9 a), at a distance $X=5 \mathrm{~m}$ from the wavemaker, corresponds to the absorption/generation boundary condition of the numerical model. The spectrum indicates that the numerical model is able to reproduce the input wave height in the frequency band between $0.15 \mathrm{~Hz}$ and $1 \mathrm{~Hz}$. In the frequency band below $0.15 \mathrm{~Hz}$, the differences in peak frequencies can be explained by the numerical boundary condition, where the reflection by the wavemaker is not included.

The second spectrum (figure $9 \mathrm{~b}$ )), at a distance $X=10 \mathrm{~m}$, shows a good match in the frequency band between $0.15 \mathrm{~Hz}$ and $1 \mathrm{~Hz}$, with some discrepancies below $0.15 \mathrm{~Hz}$. The spectrum at $X=15.31 \mathrm{~m}$ is located after the wave breaking, and even though the frequency band around the peak frequency, between $0.15 \mathrm{~Hz}$ and $0.4 \mathrm{~Hz}$ is well reproduced, the numerical model under estimates the spectral energy content above $0.4 \mathrm{~Hz}$. The numerical model spectrum at $X=20 \mathrm{~m}$ located near the shoreline, shows a frequency band which also matches the experimental data. The numerical model reproduces the energy transfer to the low frequencies near the shoreline, even though the peaks due to resonant conditions are not well reproduced.

We then consider the spectral $H_{r m s}$ cross-shore profile located at $Y=15 \mathrm{~m}$ alongshore (figure 10). The spectral $H_{r m s}$ represent the integral of the wave height spectrum, from which the energy dissipated by wave breaking can be determined. The first thing to note is that the experimental spectral $H_{r m s}$ at the open boundary at $X=5 \mathrm{~m}$ is reproduced by the numerical model. The numerical model shows an increase between $X=5 \mathrm{~m}$ and $X=10 \mathrm{~m}$, reaching its peak, and then decreases with a constant slope up to $X=19 \mathrm{~m}$. The decrease 


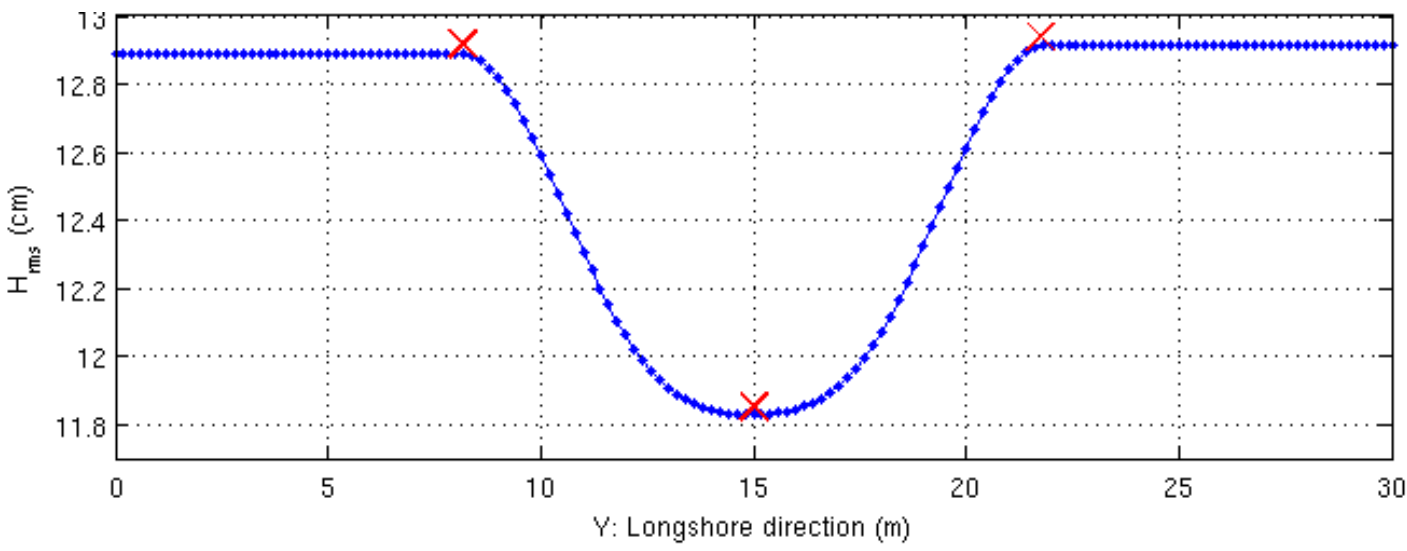

Figure 8: $H_{r m s}$ of experimental wave gauges at a distance $X=5 \mathrm{~m}$ from the wavemaker (red crosses), the thin blue line represent the $H_{r m s}$ of the interpolated input wave.

in energy dissipation corresponds to energy dissipation by wave breaking. The experimental data show that the wave height is roughly constant, up to $X=12 \mathrm{~m}$, and then decreases with an almost constant slope. The main difference between the experiment and the model is the wave breaking location, in the numerical model it occurs $2 m$ before, but the observed gradient in the spectral $H_{r m s}$ decrease is similar in both cases.

The numerical model is also validated using velocity observations. During the experiment, an Acoustic Doppler Velocimeter mounted on the sliding rail, measured the three component of the instantaneous velocities at a frequency of $64 \mathrm{~Hz}$. The ADV was located at approximately $5 \mathrm{~cm}$ from the bottom. The numerical model provides cross-shore and alongshore depth-averaged velocities, therefore we can only compare the experimental and numerical velocities qualitatively, by assuming that the ADV is outside of the boundary layer and its measurements are representative of depth-averaged velocities.

We compare the mean velocities in an alongshore profile, at a distance $X=14.71 \mathrm{~m}$ of the wavemaker, where the wave breaking has already occurred. We observe (figure 11) that the numerical model reproduced the velocity variations. Concerning the cross-shore mean velocity, the maximum off-shore velocity is located at approximately $Y=10 \mathrm{~m}$, and $Y=24 \mathrm{~m}$ where the rip channels are located, as can be seen in figure 5 . The alongshore velocities also present similarities in their variation, increasing between $Y=0 \mathrm{~m}$ and $Y=12 \mathrm{~m}$, and then decreasing for $Y>12 \mathrm{~m}$.

\section{RESULTS}

Using the numerical model, we estimated the mean velocities over a $1200 s$ simulation, and compared these circulations with experimental data. Using Lagrangian drifters, Castelle et al. [2010] obtained mean circulation velocities for different bathymetries. We compare the results over the bathymetry at $t=26: 00$ in the middle of the accretion phase, where the beach is relatively non-uniform, with two rip-channels (figure 12).

The mean circulations modelled for the first bathymetry clearly show the two circulation cells of the rip current located at $Y=11 \mathrm{~m}$, that correspond to the ones that can be seen with the drifters circulation. The center of the circulation cells in the simulation, at $X=15 \mathrm{~m}, Y=7 \mathrm{~m}$ for one, $X=16 \mathrm{~m}, Y=15 \mathrm{~m}$ for the other, are similar to the position found using drifters. The rip channel with strong offshore mean velocities, of the order of $0.1 \mathrm{~m} / \mathrm{s}$, can be seen at $Y=10 \mathrm{~m}$. The order of magnitude of the rip channel velocity in the numerical model is equivalent to the drifter circulation speed in the rip channel.

In the region of the second rip channel at $Y=26 \mathrm{~m}$, there is no data available to determine the drifter circulation. The numerical model predicts in this area another rip, but the circulation cell is not clearly observed.

Using the hydrodynamic results provided by the numerical model, we can simulate the movement of drifters induced by the wave forcing on the bathymetry at $t=26: 00$. The particle trajectories are smoothed in time over a 6 s period, for the sake of clarity.

We initialize the tracking of particles near the shoreline, at $X=20 \mathrm{~m}$, and between $4 \mathrm{~m}<Y<16 \mathrm{~m}$. This correspond to the zone between the shoreline and the two circulation cells of the rip current. The smoothed 

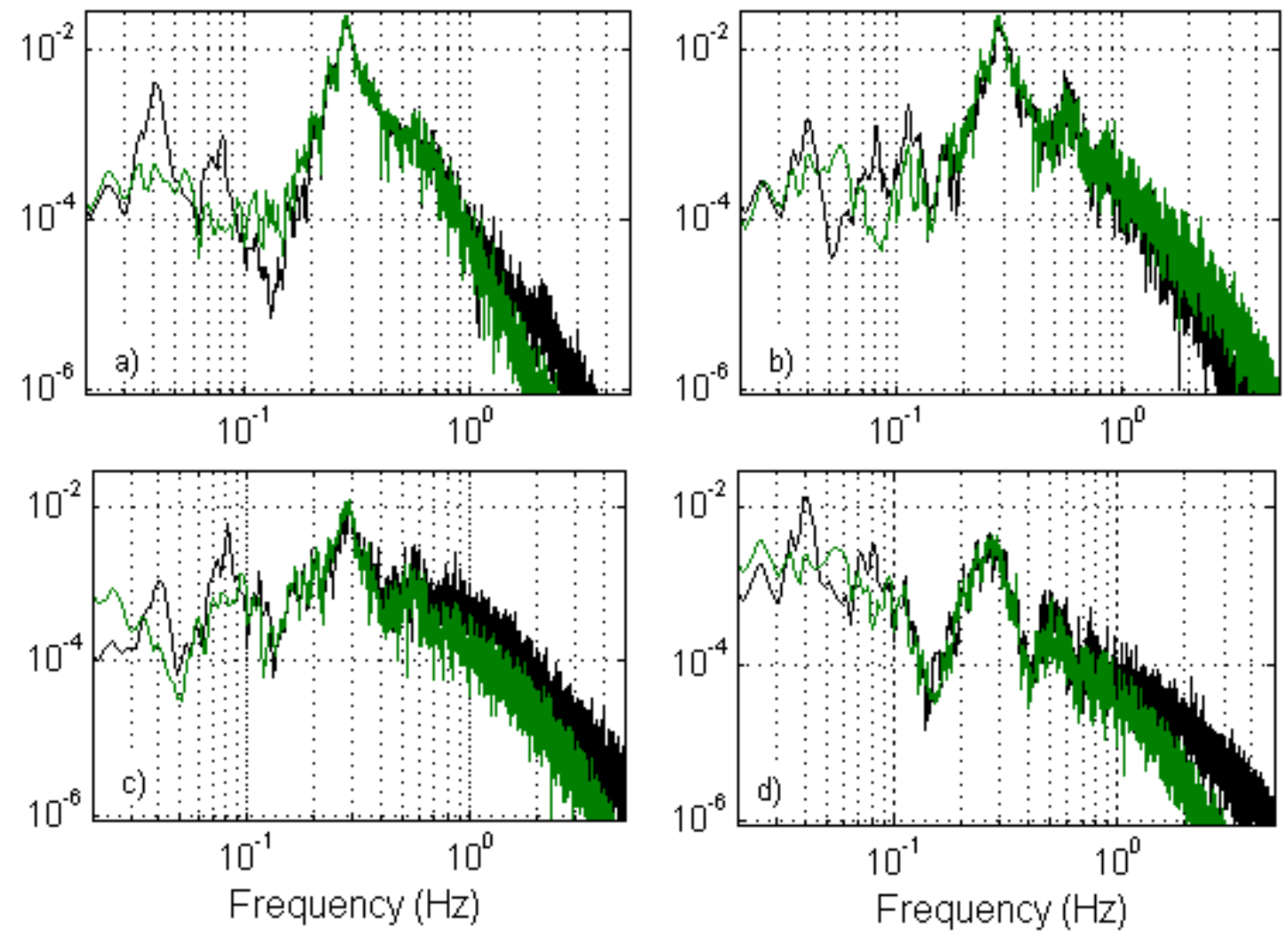

Figure 9: Spectral wave height of experimental wave gauges (black) and of the numerical model (green) at distances (a) $X=5.01 \mathrm{~m}$, (b) $X=10.31 \mathrm{~m}$, (c) $X=15.31 \mathrm{~m}$,(d) $X=20.34 \mathrm{~m}$, from the wavemaker. The alongshore distance is $Y=15 \mathrm{~m}$, at the center of the basin.

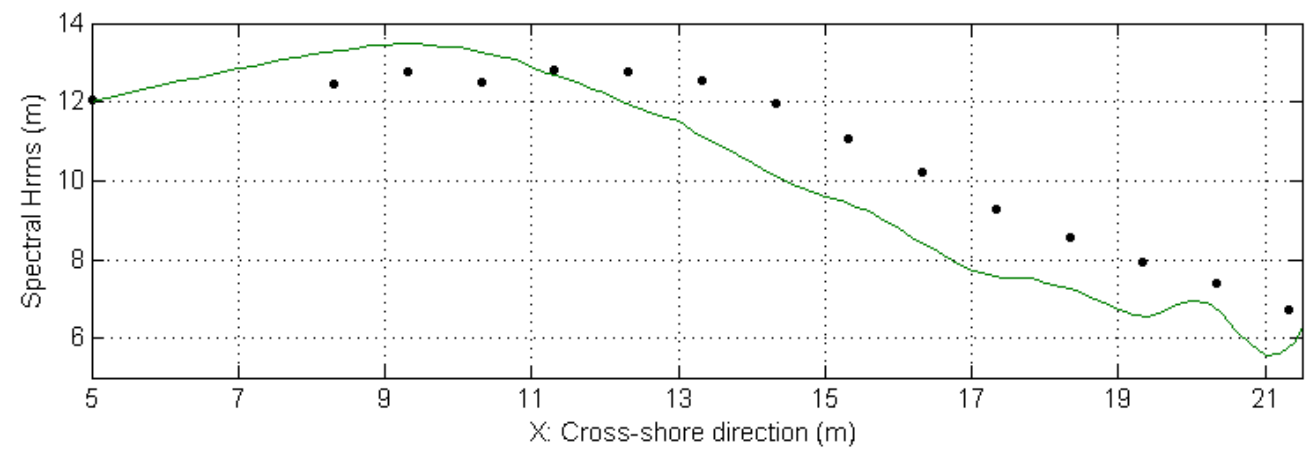

Figure 10: Cross-shore variation of Spectral $H_{r m s}$ from measured (black dots) and computed (green line) free surface time series, at an alongshore distance $Y=15 \mathrm{~m}$ 

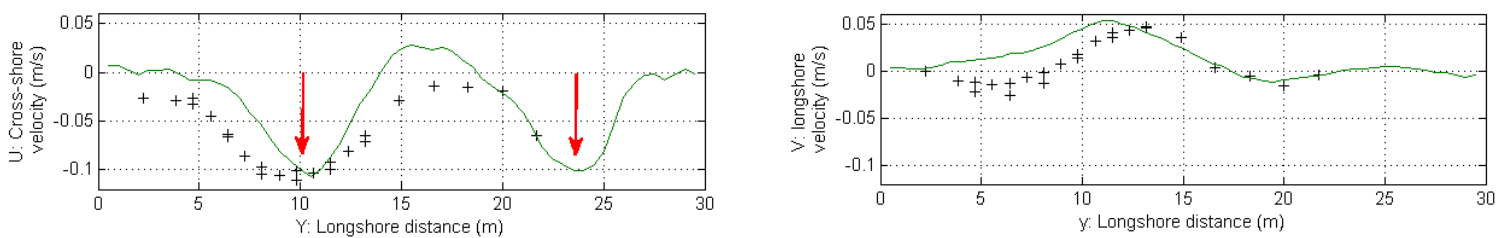

Figure 11: Cross-shore and alongshore mean velocity over the alongshore profile $Y=15 \mathrm{~m}$
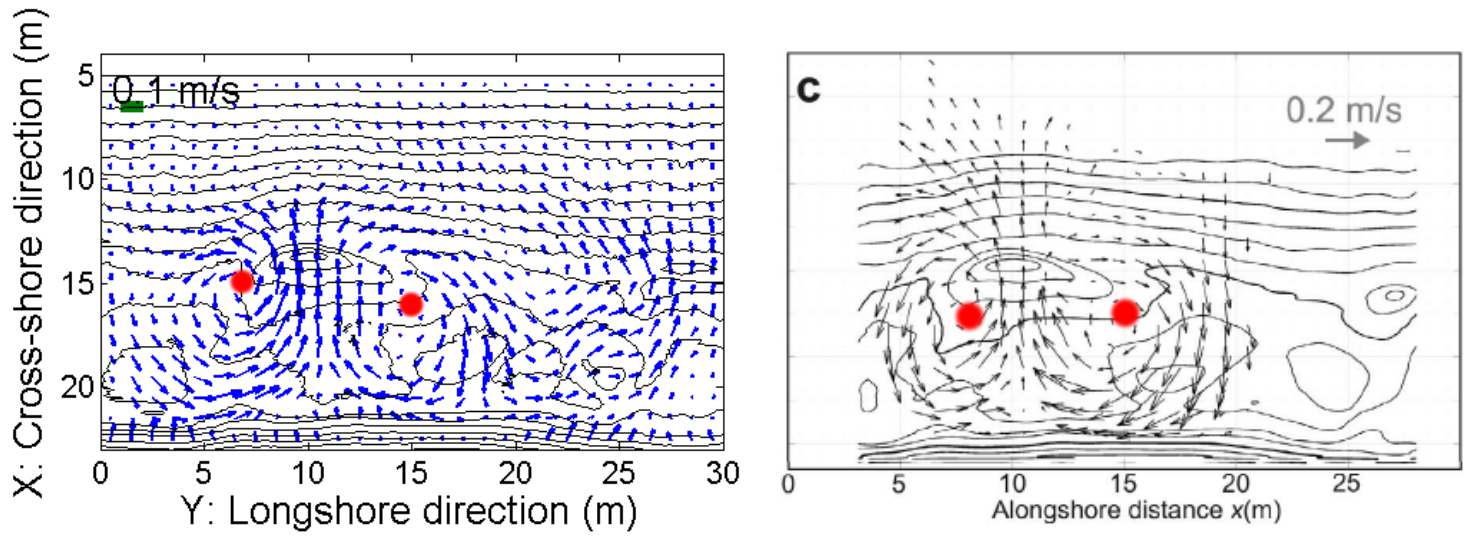

Figure 12: Mean velocity circulation over a 1200s simulation (left), and circulation estimated by drifters circulation (from Castelle et al. [2010], over a bathymetry at $t=26: 00$ ). The red dots indicates the position of the circulation cells center

trajectories of the particles (figure 13) clearly shows that almost all particles enter the rip channel, which is a preferred pathway. We then observe that some particles are caught in the recirculation cells, and perform several revolutions during the 1200 s simulation time. Some particles are ejected from the circulation when passing through the rip channel.

\section{CONCLUSION}

The 2D numerical model can reproduce mean circulations over an uneven bathymetry, with a non-uniform wave forcing. There exists an early breaking in the numerical model, but the energy dissipation rate due to wave breaking is close to the experimental data, and the wave height spectra are well reproduced. There is a good overall qualitative agreement between experimental and numerical Lagrangian drifters movement, and the circulation cells are correctly positionned compared to the experimental data. 


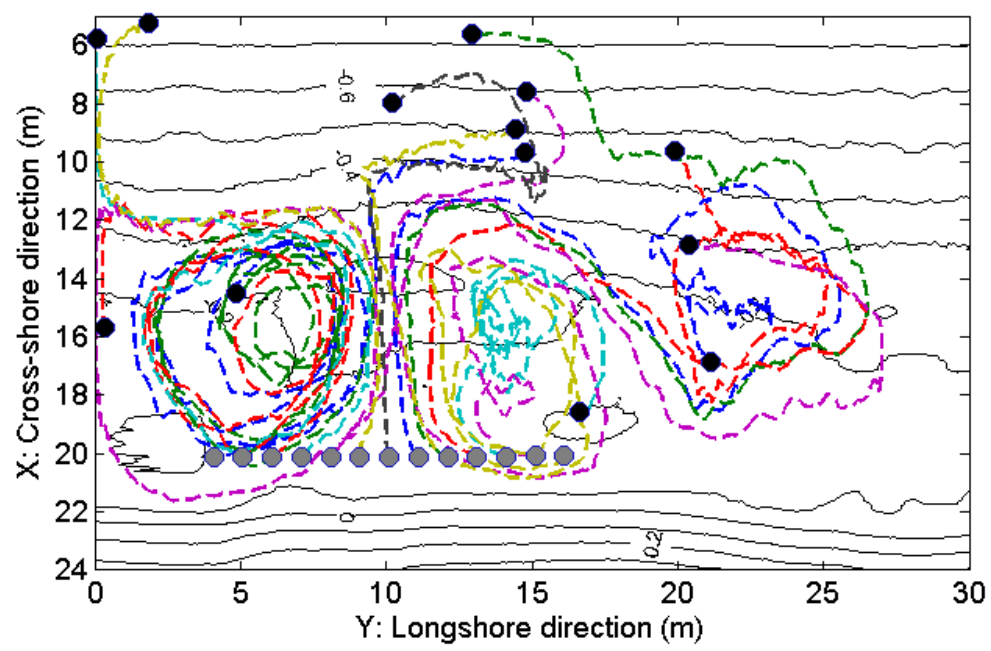

Figure 13: Drifter smoothed trajectories for a 1200 second simulation, over a bathymetry at $t=26$ : 00 . The grey dots represent the drifters' initial position, at $t=0 \mathrm{~s}$, the black dots represent their position at $t=1200 \mathrm{~s}$.

\section{ACKNOWLEDGEMENTS}

Project MODLIT (RELIEFS/INSU, SHOM-DGA) with additional financial support from COPTER (ANR) with help from SOGREAH Consultants France

This research has been funded by the CONICYT grant from Conicyt, Chile and the LEGI Laboratory,

\section{REFERENCES}

Castelle, B. Michallet, H., Marieu, V., Leckler, Dubardier, Lambert, Berni, C., Bonneton, Barthélemy, and Bouchette (2010). Laboratory experiment on rip current circulations over a moveable bed: Drifter measurements. J. Geophys. Res., 115, C12008.

Cienfuegos, Barthélemy, Bonneton (2007). A fourth-order compact finite volume scheme for fully nonlinear and weakly dispersive Boussinesq-type equations. Part II: Boundary conditions and validation. Int. J. Numer. Methods in Fluids, 53, 1423-1455.

Escauriaza, C. and Sotiropoulos, F. (2011), Lagrangian model of bed-load transport in turbulent junction flows, J. Fluid Mech, 666, 36-76.

Guerra, M. Cienfuegos, R., Escauriaza, C., Rosa (2010), Modelación numérica 2D de crecidas extremas y zonas de inundación en coordenadas curvilíneas generalizadas XXIV Congreso latinoaméricano de hidraúlica, Punta del Este, Uruguay

Liang, Q. \& Marche, F. (2009). Numerical resolution of well-balances shallow water equations with complex source terms. Adv. Water Resour., 32, 873-884.

MacMahan, J. H., Thornton, E. B.,Reniers, J.H.M. (2006). Rip current review. Coastal Engineering, 53, 191-208. 
Marche, Bonneton, Fabrie, Seguin, (2007). Evaluation of well-balance bore-capturing schemes for 2D wetting and drying processes. Int. J. Numer. Methods in Fluids, 53, 867-894.

Martínez, C., Salinas S. (2006). Morfodinámica y evolución reciente de playa Tunquén, Chile central. Revista Biología y Oceanografía Marina, 44 (1), 203-215.

Michallet, Castelle, Bouchette, Lambert, Berni, Barthélemy, Bonneton, Sous (2010). Modélisation de la morphodynamique d'une plage barrée tridimensionnelle. Proc. Journée Natl. Génie Côtier - Génie Civ., 11, 379-386.

Mignot, E. \& Cienfuegos, R. (2009). On the application of a Boussinesq model to river flows including shocks. Coast. Eng., 56, 23-31.

Reniers, A.J.H.M., MacMahan, J.H., Beron-Vera, F.J.,Olascoaga, M.J. (2010). Rip-current pulses tied to Lagrangian coherent structures. Geophysical Research Letters, 37, L05605. 